Original Research

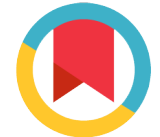

Check for updates
* For correspondence:

Homa_Babaei@kums.ac.ir

Competing interests: The authors declare that no competing interests exist.

Received: 24 December 2018 Accepted: 02 February 2018 Published: 28 February 2018

Copyright The Author(s) 2018. This article is published with open access by BioMedPress.

This article is distributed under the terms of the Creative Commons Attribution License (CC-BY 4.0) which permits any use, distribution, and reproduction in any medium, provided the original author(s) and the source are credited.

\section{Closure of patent ductus arteriosus with oral acetaminophen in preterm neonates: A randomized trial}

\section{Homa Babaei1,*, Rahele Nemati ${ }^{1,}$ Hooman Daryoshi²}

\author{
${ }^{1}$ Neonatal Department Imam Reza Hospital, Kermanshah University of Medical \\ Sciences, Kermanshah, IR Iran \\ 2Dr Kermanshahi Hospital, Kermanshah University of Medical sciences, Kermanshah, IR \\ Iran
}

\section{Abstract}

Introduction: Patent ductus arteriosus (PDA) is one of the most common cardiac problems in preterm neonates which could lead to morbidities, such as chronic lung disease, intraventricular hemorrhage and retinopathy. The aim of this study was to evaluate the effect of oral acetaminophen on closure of PDA in preterm neonates. Methods: Sixty-nine neonates with significant PDA (confirmed through echocardiography) were recruited in this study. Ibuprofen and indomethacin were contraindicated in these neonates These newborns were randomly divided into two groups of cases $(n=36)$ and controls $(n=33)$. The case group was treated with oral acetaminophen at a dose of $15 \mathrm{mg} / \mathrm{kg} /$ dose every 6 hours for 72 hours. The control group did not receive any intervention. After 72 hours, both groups were re-evaluated by echocardiography. In case of failed closure of PDA, the second course of treatment would be administration of acetaminophen. The main outcome of this study was to evaluate the rate of closure of PDA and the side effects of the acetaminophen. Results: The overall rate of PDA closure in the acetaminophen-receiving group was $94.4 \%$; the ductus arteriosus was closed in $75 \%$ of patients with the first course of treatment. Moreover, $19.4 \%$ of patients did not respond to the first course of the treatment but their ductus arteriosus was closed with the second course of acetaminophen treatment. Of the patients, $5.6 \%$ did not respond to both courses of acetaminophen treatments. For the control group, the closure rate of PDA was $15.1 \%$. Conclusion: The results of the study showed that oral acetaminophen is an effective alternative treatment for PDA in preterm neonates. 


\section{Keywords}

Acetaminophen (Paracetamol), Neonates, Patent Ductus Arteriosus

\section{Introduction}

Patent ductus arteriosus (PDA) is one of the most common cardiac problems in premature infants. The prevalence of this condition in neonates with gestational age less than 28 weeks is about 60-70\% (Koch et al., 2006). During the fetal period, the major portion of pulmonary arterial blood is shunted to aorta through the ductus arteriosus. The closure of the ductus arteriosus after birth is an essential part of the adaptation of the circulation to extrauterine life. In most term neonates, ductus arteriosus is functionally closed within 24 hours after birth (Gournay, 2011); however, patent ductus arteriosus is a common problem among preterm newborns with respiratory distress syndrome (RDS).

Ductal patency after birth in premature infants is associated with an increased risk of morbidities, such as necrotizing enterocolitis, bronchopulmonary dysplasia, retinopathy of prematurity, pulmonary hemorrhage, intraventricular hemorrhage (IVH), and neurodevelopmental disability (Dollberg et al., 2005; Bose and Laughon, 2007; Clyman et al., 2012). Currently, the first treatment for PDA includes non-specific cyclooxygenase inhibitors (indomethacin, ibuprofen) along with diuretics and fluid restriction. The chance of PDA closure after consuming ibuprofen or indomethacin is estimated to be 70 to $85 \%$ (Jones et al., 2010). One of the side effects of these two drugs is transient renal dysfunction such that creatinine clearance decreases for 6 weeks after administration of these two drugs, resulting in an increase of serum creatinine levels (Vieux et al., 2010; George et al., 2011). Animal studies on monkeys have also shown that there is an association between ibuprofen consumption and decrease in width of the nephrogenic zone in kidneys which may reduce nephrogenesis (Sutherland et al., 2012).

On the other hand, there are several contraindications for ibuprofen and indomethacin administration including thrombocytopenia, IVH, renal failure (due to decreased renal perfusion), necrotizing enterocolitis (NEC), concomitant administration of corticosteroids (risk of perforation of the intestines) and hyperbilirubinemia (competitive binding of albumin) (Soligard et al., 2010). Most of these contraindications are related to the pharmacological effects of these drugs (Anderson, 2008). Therefore, it is more desirable to administer drugs with less contraindications and side effects.

Several studies have shown that administration of acetaminophen at a dose of $60 \mathrm{mg} / \mathrm{kg} /$ day leads to closure of the PDA (Hammerman et al., 2011; Oncel et al., 2013; Yurttutan et al., 2013). Through inhibiting peroxidase sites, 
acetaminophen decreases prostaglandins and thus closes the PDA. Patent ductus arteriosus could easily be detected and measured through echocardiography. Treatment of this condition is usually carried out in the first days of birth through non-steroidal anti-inflammatory drugs, such as ibuprofen or indomethacin (Kliegman and Nelson, 1898). As mentioned, however, due to several side effects and contraindications, these drugs cannot be prescribed for some infants. Several studies have suggested the administration of acetaminophen as an alternative drug.

Therefore, in light of the above-mentioned suggestions, in this study we evaluated the administration of acetaminophen as an alternative therapeutic drug for preterm neonates with open arterial ducts who showed contraindications to treatment with ibuprofen or indomethacin.

\section{Materials-Methods}

This clinical trial was conducted on all preterm neonates with gestational age of 34 weeks or less, and who were less than 14 days old when admitted to the Neonatal Intensive Care Unit (NICU) of the Imam Reza Hospital in Kermanshah City (Iran) during 2015. The inclusion criteria were as follows:

1) clinical symptoms of PDA including tachycardia, active pericardium, systolic or continuous murmur, wide pulses, increased oxygen dependency or hypercapnia;

2) significant PDA diagnosis through echocardiography; and

3) contraindications of ibuprofen or indomethacin consumption from oliguria (urine output $<1 \mathrm{cc} / \mathrm{kg} / \mathrm{hr}$ ), serum creatinine $>1.8 \mathrm{mg} / \mathrm{dl}$, platelet count $<50,000$, hyperbilirubinemia requiring blood exchange, and/or necrotizing enterocolitis.

It should be noted that the echocardiographic criteria for initiating the treatment was a ductal size of greater than $1.5 \mathrm{~mm}$, which was considered significant PDA. Exclusion criteria were as follows: ductal dependent congenital heart diseases (as PDA is needed to maintain blood flow), life-threatening infections, severe hepatic failure (increased liver enzyme levels more than twice the normal upper limit), and/or grade 3 and $4 \mathrm{IVH}$.

After obtaining consent from the parents, the neonates were enrolled in the study and randomly divided into case and control groups (Fig. 1). In the case group, neonates, were treated with oral drops of acetaminophen (manufactured by Behsa) at a dose of $15 \mathrm{mg} / \mathrm{kg} /$ dose every 6 hours for 72 hours. No intervention was carried out in the control group. After 72 hours, both groups 
underwent another echocardiography to determine the state of ductus arteriosus. The neonates enrolled in the case group were monitored in the same fashion before administration of acetaminophen until an hour after administration for hypothermia; this was carried out every 30 minutes. Also, before and 72 hours after initiating acetaminophen treatment, liver enzymes were measured. If the patent ductus arteriosus was observed in the second echocardiography, another 3-day treatment with acetaminophen would be repeated in the case group. At the end of the third day, the echocardiography would be re-conducted. Those patients who did not respond well to the first and second course of acetaminophen were considered as candidates for surgical treatment.

The main outcome of this study was the ductus arteriosus closure rate as well as the evaluation of side effects of acetaminophen; the secondary outcome of the study was to evaluate acetaminophen safety. The data was analyzed via SPSS 22 software with use of independent t-test (in normal data distribution cases) or Mann-Whitney (in abnormal data distribution cases), and Chi-square test. The Kolmogorov-Smirnov test was used to determine the normality of the values of different variables.

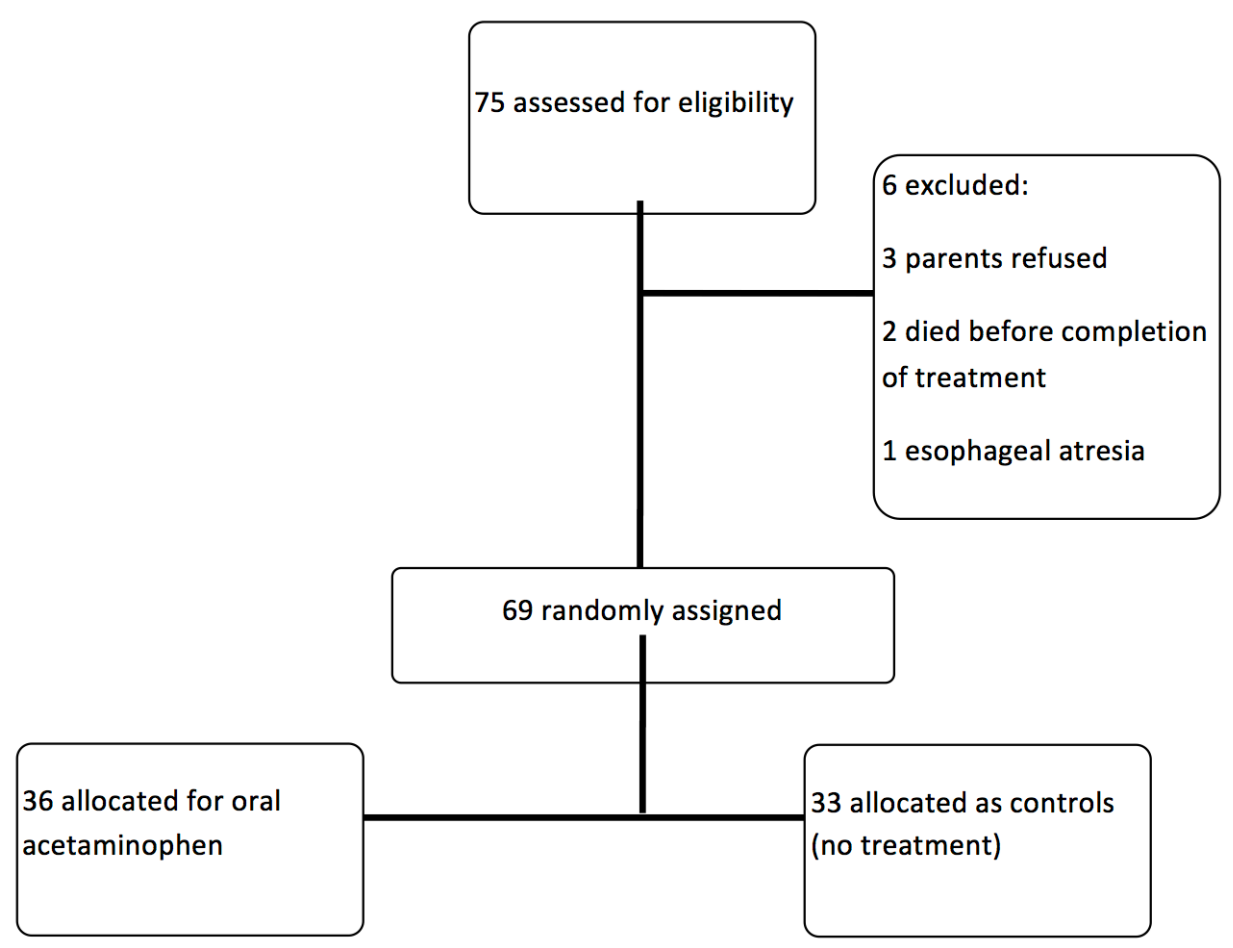

Figure 1. Flow diagram of study. 


\section{Results}

This study was conducted on 75 preterm neonates with gestational age of 34 weeks or less who had the inclusion criteria and were admitted to the NICU of Imam Reza Hospital in Kermanshah, Iran during 2015. Of these neonates, 6 were excluded ( 3 cases were excluded due to parents' discontent, 2 cases died before the termination of the treatment period as a result of underlying illnesses, and 1 case was excluded due to esophageal atresia problems). Therefore, 69 neonates remained in the study. After selecting the patients, they were randomly divided into two groups of cases (36) and controls (33). Demographic findings, including birth weight, gestational age, gender, ductal diameter and postnatal age at the time of study, were not statistically significant in the two groups (Table 1).

Table 1. Baseline clinical characteristics

\begin{tabular}{|c|c|c|c|c|}
\hline \multirow{3}{*}{ Gender } & & $\begin{array}{l}\text { Acetaminophen group } \\
\qquad n=36\end{array}$ & $\begin{array}{c}\text { Control group } \\
\qquad n=33\end{array}$ & P-value \\
\hline & Male & $15(42 \%)$ & $13(40 \%)$ & \multirow{2}{*}{0.455} \\
\hline & Female & $21(58 \%)$ & $20(60 \%)$ & \\
\hline \multicolumn{2}{|c|}{ Gestational age (week) } & $\begin{array}{c}32.11 \pm 2.09 \\
(26-34)\end{array}$ & $\begin{array}{c}31.2 \pm 1.8 \\
(26-34)\end{array}$ & 0.343 \\
\hline \multicolumn{2}{|c|}{ Mean birth weight (g) } & $\begin{array}{c}1998.26 \pm 525.73 \\
(900-2900)\end{array}$ & $\begin{array}{c}1917 \pm 429.6 \\
(850-2800)\end{array}$ & 0.576 \\
\hline \multicolumn{2}{|c|}{$\begin{array}{l}\text { Internal ductal diameter } \\
(\mathrm{mm})\end{array}$} & $\begin{array}{l}2.29 \pm 0.23 \\
(1.55-2.7)\end{array}$ & $2.31 \pm 035$ & 0.654 \\
\hline \multicolumn{2}{|c|}{$\begin{array}{l}\text { Mean age at the start of } \\
\text { the first course (day) }\end{array}$} & $\begin{array}{c}4.6 \pm 1.7593 \\
(2-10)\end{array}$ & $\begin{array}{c}5.1 \pm 1.8823 \\
(2-11)\end{array}$ & 0.488 \\
\hline
\end{tabular}

Table 2. Efficacy of oral acetaminophen for PDA closure

\begin{tabular}{|l|c|c|c|}
\hline & $\begin{array}{c}\text { Acetaminophen group } \\
\mathbf{n = 3 6}\end{array}$ & $\begin{array}{c}\text { Control group } \\
\mathbf{n = 3 3}\end{array}$ & P-value \\
\hline Overall closure rate (\%) & $34(94.4 \%)$ & $5(15.1 \%)$ & 0.001 \\
\hline Primary closure rate & $27(75 \%)$ & $5(15.1 \%)$ & 0.002 \\
\hline Secondary closure rate & $7(19.4 \%)$ & $0(0)$ & 0.021 \\
\hline
\end{tabular}


The overall rate of PDA closure in the acetaminophen-receiving group was 94.4\% (34 out of 36 newborns); the ductus arteriosus was closed in $75 \%$ (27 neonates) after the first treatment course. In addition, 19.4\% (7 newborns) did not respond to the first course of the treatment but their ductus arteriosus was closed following the second course of treatment, and 2 neonates (5.6\%) did not respond to both courses of acetaminophen treatment. The closure rate of PDA in the control group was $15.1 \%$ (5 newborns) (Table 2).

There was no significant association observed between the rate of PDA closure and gestational age, birth weight or postnatal age at the time of admission. However, there was a significant difference between the effectiveness of oral acetaminophen on the rate of PDA closure in male and female preterm infants $(p=0.024) ;$ all the infants who did not respond to acetaminophen therapy were females (Table 3). During the study, none of the newborns experienced complications. Also, hypothermia and abnormality of liver enzymes were not observed in any of the infants.

Table 3. The association between gender, gestational age, birth weight, age at the start of acetaminophen course, and ductal diameter to treatment response in the case group

\begin{tabular}{|c|c|c|c|c|}
\hline & & $\begin{array}{l}\text { Response to } \\
\text { acetaminophen } \\
\qquad n=34\end{array}$ & $\begin{array}{l}\text { No response to } \\
\text { acetaminophen } \\
\qquad n=2\end{array}$ & P-value \\
\hline \multirow{2}{*}{ Gender } & Male & $15(100 \%)$ & $0(0 \%)$ & \multirow{2}{*}{0.024} \\
\hline & Female & $19(90.5 \%)$ & $2(9.5 \%)$ & \\
\hline \multirow{4}{*}{ Gestational age (week) } & $<28$ & $2(100 \%)$ & $0(0 \%)$ & \multirow{4}{*}{0.832} \\
\hline & $28-30$ & $5(83.3 \%)$ & $1(16.7 \%)$ & \\
\hline & $30-32$ & $7(87.5 \%)$ & $1(12.5 \%)$ & \\
\hline & $>32$ & $20(100 \%)$ & $0(0 \%)$ & \\
\hline \multirow{3}{*}{ Birth weight (g) } & $<1500$ & $7(\% 87.5)$ & $1(12.5 \%)$ & \multirow{3}{*}{0.611} \\
\hline & $\begin{array}{c}1500-250 \\
0\end{array}$ & $22(95.6 \%)$ & $1(4.3 \%)$ & \\
\hline & $>2500$ & $5(100 \%)$ & $\mathrm{O}(0 \%)$ & \\
\hline \multirow{2}{*}{$\begin{array}{l}\text { Age at the start of the } \\
\text { first course (day) }\end{array}$} & $<7$ & $31(94 \%)$ & $2(6 \%)$ & \multirow{2}{*}{1} \\
\hline & $>7$ & $3(100 \%)$ & $(0 \%)$ & \\
\hline \multirow{3}{*}{ Ductal diameter (mm) } & $1.5-2$ & $4(100 \%)$ & $0(0 \%)$ & \multirow{3}{*}{$<0.001$} \\
\hline & $2-2.5$ & $28(100 \%)$ & $0(0 \%)$ & \\
\hline & $>2.5$ & $0(0 \%)$ & 2 & \\
\hline
\end{tabular}




\section{Discussion}

The results of this study show that the chance of PDA closure through administration of oral acetaminophen in preterm infants is $94.4 \%$, which indicates the high effectiveness of acetaminophen on ductus arteriosus closure in preterm infants. Therefore, in this study we show that acetaminophen could be prescribed as an alternative drug therapy for premature neonates in which the arterial duct is open and ibuprofen or indomethacin is contraindicated.

Naturally, the closure of PDA in neonates during the primary hours after birth is the result of an increase in blood oxygen levels and a decrease in vasodilators, such as prostaglandin E2 and I2 (Dang et al., 2013). Indomethacin and ibuprofen are two selective treatments for PDA; they both inhibit the synthesis of prostaglandins thereby inducing PDA closure. However, both of these drugs induce gastrointestinal and renal side effects. Moreover, acetaminophen inhibits prostaglandin synthesis. Although the exact mechanism of action of acetaminophen is still controversial, this drug appears to act on the peroxidase segment of the enzyme (Green et al., 1989; Lucas et al., 2005).

In the present study, 5.6\% (2 infants) of the newborns even after receiving two courses of treatment with acetaminophen did not show ductus arteriosus closure. Both of these infants were female, indicating a significant association between gender and acetaminophen treatment response $(p=0.024)$. Also, the size of PDA in both of these two infants was greater than $2.5 \mathrm{~mm}$, which could explain the unresponsiveness to acetaminophen. No acetaminophen-related complications were observed in the present study.

In several studies carried out since 2012, using acetaminophen has been suggested by many authors as an alternative treatment for PDA in preterm infants. In most of these studies, the success rate of acetaminophen in PDA closure was greater than 70\%; similarly, no acetaminophen-related side effects were seen (Le et al., 2015). In a study conducted by DeMauro et al. in 2014, the PDA closure rate was $72.5 \%$; this study suggested acetaminophen as a therapeutic alternative for PDA management (DeMauro and Wright, 2014). Tekgündüz et al. compared the effects of two different doses of paracetamol (acetaminophen): $15 \mathrm{mg} / \mathrm{kg}$ every 6 hours or $10 \mathrm{mg} / \mathrm{kg}$ every 8 hours. The evaluated 13 neonates with PDA and showed that PDA closure rate in the high dose $(15 \mathrm{mg} / \mathrm{kg})$ group was $76.9 \%$ while in the low dose $(10 \mathrm{mg} / \mathrm{kg})$ group, PDA closure rate was estimated to be $83.3 \%$ (Tekgündüz et al., 2015).

Another study, by Nadir E et al. in 2014, was conducted on 7 neonates who did not respond to ibuprofen treatment and who were prescribed paracetamol. After taking paracetamol, PDA was closed in 5 of these newborns. In 1 newborn it was re-opened but then successfully treated through paracetamol administration. Surgical procedures were performed for the remaining 2 patients. No blood and biochemical disorders were observed in this study (Nadir et al., 2014). Sancak $S$ et al. compared the effects of oral and intravenous paracetamol on the rate of 
PDA closure in preterm infants in 2014. Their results showed that the PDA closure rate in the oral paracetamol group was higher than that of the intravenous paracetamol group ( $88 \%$ vs. $70 \%$ ), but this difference was not statistically significant. The authors stated that more research studies with greater sample sizes were required to discern the difference (Sancak et al., 2016).

In a clinical trial conducted on 90 preterm infants in 2014, Oncel et al. observed that after a course of treatment, PDA was closed in $77.5 \%$ of the newborns in an ibuprofen-treated group, whereas in the paracetamol group, PDA was closed in $72.5 \%$ of the neonates. In that study, it was stated that paracetamol could be regarded as an alternative treatment for PDA treatment (Oncel et al., 2014). In another study, this one carried out by Dang et al. in 2013, two groups of newborns with the same sample size were treated with acetaminophen or oral ibuprofen at a dose of $15 \mathrm{mg} / \mathrm{kg}$ every 6 hours for 3 days. The results showed that $81 \%$ of the newborns in the acetaminophen group and $78 \%$ in the ibuprofen group experienced PDA closure. Also, complications such as hyperbilirubinemia and gastrointestinal bleeding were not observed in the acetaminophen group (Dang et al., 2013). In another clinical trial in 2013, Rahul Sinha et al. reported that administration of ibuprofen or indomethacin failed to close PDA. However, within 48 hours of acetaminophen administration, PDA was closed in all patients. Also, no side effects were observed in the newborns (Sinha et al., 2013).

\section{Conclusion}

The side effects of non-steroidal anti-inflammatory drugs side effects and their likely failure to induce PDA closure necessitates the need for an alternative drug. Given the fact that acetaminophen is a cost-effective drug that can be administered orally and has no observed side effects in the newborns, it is suitable as the first line of PDA treatment. It remains to be seen if its effectiveness can be demonstrated in larger scale studies.

\section{Abbreviations}

NEC : necrotizing enterocolitis

NICU : Neonatal Intensive Care Unit

PDA:Patent ductus arteriosus

RDS: respiratory distress syndrome 


\section{Acknowledgements}

We would like to express our sincere gratitude to the staff of Neonatal Intensive Care Unit (NICU) of the Imam Reza Hospital in Kermanshah City (Iran)

\section{Author Contribution}

$H B, R N$ and $H D$ designed the study. $H B$ and $H D$ processed the data. $H B, R N$ and $H D$ performed the statistical analysis. $\mathrm{HB}$ and $\mathrm{HD}$ interpreted the results. $\mathrm{HB}, \mathrm{RN}$ and $\mathrm{HD}$ wrote the first draft. HB and HD revised the final draft. All authors read and approved the final manuscript.

\section{References}

Waldemar A. Carlo, Namasivayam A. Respiratory Distress Syndrome (Hyaline Membrane Disease) In: kliegman RM, Stanton BF, Geme JW, Schor NF, BehrmanRE. Nelson text book of pediatrics.19th ed. Philadelphia: saunders, 2011,587.

Anderson, B. J. (2008). Paracetamol (Acetaminophen): Mechanisms of action. Paediatric Anaesthesia, 18(10), 915-921. https://doi.org/10.1111/j.1460-9592.2008.02764.x PMID:18811827Bose, C. L., \& Laughon, M. M. (2007). Patent ductus arteriosus: Lack of evidence for common treatments. Archives of Disease in Childhood. Fetal and Neonatal Edition, 92(6), F498-F502. https://doi.org/10.1136/adc.2005.092734 PMID:17951552

Clyman RI, Couto J, Murphy GM. Patent ductus arteriosus: are current neonatal treatment options better or worse than no treatment at all? Seminars in perinatology, 2012. Elsevier, 123-9. https://doi.org/10.1053/j.semperi.2011.09.022

Dang, D., Wang, D., Zhang, C., Zhou, W., Zhou, Q., \& Wu, H. (2013). Comparison of oral paracetamol versus ibuprofen in premature infants with patent ductus arteriosus: A randomized controlled trial. PLoS One, 8(11), e77888. https://doi.org/10.1371/ journal.pone.0077888 PMID:24223740

DeMauro, S. B., \& Wright, C. J. (2014). Acetaminophen: A possible alternative to ibuprofen in patent ductus arteriosus closure. The Journal of Pediatrics, 165(1), 209210. https://doi.org/10.1016/j.jpeds.2014.04.025 PMID:24973162

Dollberg, S., Lusky, A., \& Reichman, B. (2005). Patent ductus arteriosus, indomethacin and necrotizing enterocolitis in very low birth weight infants: A population-based study. Journal of Pediatric Gastroenterology and Nutrition, 40(2), 184-188. https://doi.org/ 10.1097/00005176-200502000-00019 PMID:15699694

George, I., Mekahli, D., Rayyan, M., Levtchenko, E., \& Allegaert, K. (2011). Postnatal trends in creatinemia and its covariates in extremely low birth weight (ELBW) neonates. Pediatric Nephrology (Berlin, Germany), 26(10), 1843-1849. https://doi.org/10.1007/ s00467-011-1883-0 PMID:21499946

Gournay, V. (2011). The ductus arteriosus: Physiology, regulation, and functional and congenital anomalies. Archives of Cardiovascular Diseases, 104(11), 578-585. https:// doi.org/10.1016/j.acvd.2010.06.006 PMID:22117910

Grèen, K., Drvota, V., \& Vesterqvist, O. (1989). Pronounced reduction of in vivo prostacyclin synthesis in humans by acetaminophen (paracetamol). Prostaglandins, 37(3), 311-315. https://doi.org/10.1016/0090-6980(89)90001-4 PMID:2664901 
Hammerman, C., Bin-Nun, A., Markovitch, E., Schimmel, M. S., Kaplan, M., \& Fink, D. (2011). Ductal closure with paracetamol: A surprising new approach to patent ductus arteriosus treatment. Pediatrics, 128(6), e1618-e1621. https://doi.org/10.1542/peds. 2011-0359 PMID:22065264

Jones L, Craven P, Attia J, et al (2010). Network meta-analysis of indomethacin versus ibuprofen versus placebo for PDA in preterm infants. Archives of Disease in ChildhoodFetal and Neonatal Edition, fetalneonatal168682.

Koch, J., Hensley, G., Roy, L., Brown, S., Ramaciotti, C., \& Rosenfeld, C. R. (2006). Prevalence of spontaneous closure of the ductus arteriosus in neonates at a birth weight of 1000 grams or less. Pediatrics, 117(4), 1113-1121. https://doi.org/10.1542/ peds.2005-1528 PMID:16585305

Le, J., Gales, M. A., \& Gales, B. J. (2015). Acetaminophen for patent ductus arteriosus. The Annals of Pharmacotherapy, 49(2), 241-246. https://doi.org/ 10.1177/1060028014557564 PMID:25352038

Lucas, R., Warner, T. D., Vojnovic, I., \& Mitchell, J. A. (2005). Cellular mechanisms of acetaminophen: Role of cyclo-oxygenase. The FASEB Journal, 19(6), 635-637. https:// doi.org/10.1096/fj.04-2437fje PMID:15705740

Nadir, E., Kassem, E., Foldi, S., Hochberg, A., \& Feldman, M. (2014). Paracetamol treatment of patent ductus arteriosus in preterm infants. Journal of Perinatology, 34(10), 748-749. https://doi.org/10.1038/jp.2014.96 PMID:24854626

Oncel, M. Y., Yurttutan, S., Degirmencioglu, H., Uras, N., Altug, N., Erdeve, O., \& Dilmen, U. (2013). Intravenous paracetamol treatment in the management of patent ductus arteriosus in extremely low birth weight infants. Neonatology, 103(3), 166-169. https:// doi.org/10.1159/000345337 PMID:23258386

Oncel MY, Yurttutan S, Erdeve O, et al (2014). Oral paracetamol versus oral ibuprofen in the management of patent ductus arteriosus in preterm infants: a randomized controlled trial. The Journal of pediatrics, 164, 510-4. e1. https://doi.org/10.1016/ j.jpeds.2013.11.008

Sancak, S., Gokmen Yildirim, T., Topcuoglu, S., Yavuz, T., Karatekin, G., \& Ovali, F. (2016). Oral versus intravenous paracetamol: Which is better in closure of patent ductus arteriosus in very low birth weight infants? The Journal of Maternal-Fetal \& Neonatal Medicine, 29(1), 135-139. https://doi.org/10.3109/14767058.2014.989829 PMID: 25471090

Sinha, R., Negi, V., \& Dalal, S. S. (2013). An interesting observation of PDA closure with oral paracetamol in preterm neonates. Journal of Clinical Neonatology, 2(1), 30-32. https://doi.org/10.4103/2249-4847.109245 PMID:24027742

Soligard, H. T., Nilsen, O. G., \& Bratlid, D. (2010). Displacement of bilirubin from albumin by ibuprofen in vitro. Pediatric Research, 67(6), 614-618. https://doi.org/ 10.1203/PDR.0b013e3181da7578 PMID:20216106

Sutherland, M. R., Yoder, B. A., McCurnin, D., Seidner, S., Gubhaju, L., Clyman, R. I., \& Black, M. J. (2012). Effects of ibuprofen treatment on the developing preterm baboon kidney. American Journal of Physiology. Renal Physiology, 302(10), F1286-F1292. https://doi.org/10.1152/ajprenal.00216.2011 PMID:22357916

Tekgündüz, K. Ş., Ceviz, N., Caner, I., Olgun, H., Demirelli, Y., Yolcu, C., . . . Kara, M. (2015). Intravenous paracetamol with a lower dose is also effective for the treatment of patent ductus arteriosus in pre-term infants. Cardiology in the Young, 25(6), 1060-1064. https://doi.org/10.1017/S1047951114001577 PMID:25160728 
Vieux R, Fresson J, Guillemin F, et al (2010). Perinatal drug exposure and renal function in very preterm infants. Archives of Disease in Childhood-Fetal and Neonatal Edition, fetalneonatal197699.

Yurttutan, S., Oncel, M. Y., Arayicı, S., Uras, N., Altug, N., Erdeve, O., \& Dilmen, U. (2013). A different first-choice drug in the medical management of patent ductus arteriosus: Oral paracetamol. The Journal of Maternal-Fetal \& Neonatal Medicine, 26(8), 825-827. https://doi.org/10.3109/14767058.2012.755162 PMID:23205872 